\title{
DESIGN, CONSTRUCTION AND PERFORMANCE OF SEEPAGE BARRIERS FOR DAMS ON CARBONATE FOUNDATIONS
}

\author{
Dr. Donald A. Bruce, C.Eng. ${ }^{1}$ \\ Trent L. Dreese, P.E. ${ }^{2}$ \\ David B. Wilson, P.E. ${ }^{3}$
}

\begin{abstract}
The design, construction and performance of concrete cut-offs, and grout curtains, as dam seepage remediations in carbonate foundations is reviewed. Recent experiences when attempting to build concrete cut-offs through hard and highly permeable rock masses have led the authors to develop the concept of "composite cut-offs" for seepage control. A campaign of high quality drilling, permeability testing and grouting is first conducted to pretreat the very permeable and/or clay-filled zones, to seal the clean fissures, and to provide an extremely detailed geological basis upon which to design the location and extent of the subsequent concrete wall (if in fact needed). Bearing in mind that the average cost of a concrete wall is many times that of a grouted cut-off, and that there is currently a shortfall in industry capacity to construct the former, the concept of a "composite wall" is logical, timely and cost effective.
\end{abstract}

\section{INTRODUCTION}

As documented by Weaver and Bruce (2007), grout curtains have been used in the U.S. to control seepage in rock masses under and around dams of all types since the 1890's. For a variety of understandable, if not always laudable reasons, the long-term performance of many of these curtains has not been satisfactory, especially in lithologies containing soluble and/or erodible materials. Foundation remediation in such instances traditionally involved regrouting, often of course, using the same means, methods and materials whose defects were the underlying cause of the inadequacy in the first place.

Disillusionment on the part of owners and engineers with the apparent inability of these traditional grouting practices to provide a product of acceptable efficiency and durability led to the chorus of "grouting doesn't work" voices in the industry from the mid-1970's onwards. The fact that effective and durable grout curtains were being installed successfully elsewhere in the world, using different perspectives on design, construction and contractor procurement processes, largely escaped the attention of the doubters who, for all their other and obvious qualities, exhibited technological xenophobia.

1 President, Geosystems, L.P., P.O. Box 237, Venetia, PA 15367, U.S.A.; Phone: (724) 942-0570; Fax: (724) 942-1911; Email: dabruce@geosystemsbruce.com.

2 Vice President, Gannett Fleming Inc., 207 Senate Avenue, Camp Hill, PA 17011, U.S.A.; Phone: (717) 763-7211 x2686; Fax: (717) 303-0346; Email: tdreese@gfnet.com.

3 Manager, Earth Science and Hydraulics Practice, Gannett Fleming, Inc., P.O. Box 67100, Harrisburg, PA 17106; Phone: (717) 763-7211; Fax: (717) 763-1808; Email: dwilson@gfnet.com. 
Partly as a result of the anti-grouting lobby, equally in response to indisputable geological realities and challenges and building on technical advances in "slurry wall" techniques, the concept and reality of "positive cut-offs" became the mantra for major embankment dam foundation rehabilitation in North America from 1975 onwards. Such walls, built through and under existing dams by either the panel wall technique, or secant large diameter piles, comprise some type of concrete, ranging from high strength to plastic. In contrast to grout curtains, where well over $90 \%$ of the cut-off is, in fact, the virgin, in situ rock, these "positive" cut-offs were, in theory, built of $100 \%$ pre-engineered material of well-defined properties.

Such "positive" walls are essential to provide long-term cut-off across karstic features which contain residual, potentially erodible material: such material simply cannot be grouted with a degree of uniformity and confidence to assure satisfactory long-term performance. The list of successful projects executed to date in the U.S. is extremely impressive (Bruce et al., 2006; Bruce 2007), with many having been installed in carbonate terrains of varying degrees of karstification. To date almost 7.5 million square feet of concrete cut-off have been installed in 20 projects.

From the mid-1980's - albeit in Europe (Lombardi 2003) - a new wave of dam grouting concepts began to emerge. Given that most of the leading North American practitioners had close corporate and/or professional and personal links with this insurgency, it is not surprising that their heretofore moribund industry began to change. By the time of the seminal 2003 ASCE grouting conference in New Orleans, the revolution in North American practice for dam foundation grouting had been clearly demonstrated (Wilson and Dreese, 2003; Walz et al., 2003). The concept of a Quantitatively Engineered Grout Curtain was affirmed. Differences in opinion and philosophies with the great European practitioners such as Lombardi, the architect of the GIN Method, were not necessarily resolved: they were debated between equals and the respective opinions fairly acknowledged.

It is therefore the case that, in North America, there is now expertise and experience of an unparalleled level in both grout curtains and concrete cut-off walls. This is particularly serendipitous given that the dollar requirement for the application of both technologies in Federal dams alone in the next 5 years - is of an order equivalent to the aggregate of the preceding 40 years (Halpin, 2007).

This paper presents a review of the current state-of-practice in each of these two technologies. The paper describes how these techniques can be combined in the concept of a "composite cut-off" which has potentially extraordinary benefits to owners in the financial sense, while still assuring the highest verifiable standards of performance and durability in the field. 


\section{CUT-OFFS}

Investigations, Design, Specifications and Contractor Procurement

- Intensive, focused site investigations are essential as the basis for cut-off design and contractor bidding purposes. In particular, these investigations must not only identify rock mass lithology, structure and strength ("rippability"), but also the potential for loss of slurry during panel excavation. This has not always been done, and cost and schedule have suffered accordingly on certain major projects.

- Special considerations have had to be made when designing cut-offs which must contact existing concrete structures, or which must be installed in very deep-sided valley sections, or which must toe in to especially strong rock.

- "Test Sections" have proved to be extremely valuable, especially for the contractor to refine his means, methods and quality control systems. Such programs have also given the dam safety officials and owners the opportunity to gain confidence and understanding in the response of their dams to the invasive surgery that constitutes cut-off wall construction. Furthermore, such programs have occasionally shown that the foreseen construction method was practically impossible (e.g., a hydromill at Beaver Dam, AR) or that significant facilitation works (e.g., pregrouting of the wall alignment at Mississinewa Dam, IN, Clearwater Dam, MO, and Wolf Creek Dam, KY) were required.

- Every project has involved a high degree of risk and complexity and has demanded superior levels of collaboration between designer and contractor. This situation has been best satisfied by procuring a contractor on the basis of "best value," not "low bid." This involves the use of RFP's (Requests for Proposals) with a heavy emphasis on the technical submittal and, in particular, on corporate experience, expertise and resources, and the project-specific Method Statement. These projects are essentially based on Performance, as opposed to Prescriptive Specifications . Partnering arrangements (which are post-contract) have proved very useful to both parties when entered into with confidence, enthusiasm, and trust.

\section{Construction and $\mathrm{QA} / \mathrm{QC}$}

- The specialty contractors have developed a wide and responsive variety of equipment and techniques to assure penetration and wall continuity in a wide variety of ground conditions. More than one technique, e.g., clamshell followed by hydromill, has frequently been used on the same project and especially where bouldery conditions have been encountered.

- Cut-offs can be safely constructed with high lake levels, provided that the slurry level in the trench can be maintained a minimum of 3 feet higher. In extreme geological conditions, this may demand pretreatment of the embankment (e.g., Mud Mountain Dam, WA) or the rock mass (Mississinewa Dam, IN) to guard against massive, sudden slurry loss.

- For less severe geological conditions, contractors have developed a variety of defenses against slurry losses of smaller volume and rate by providing large slurry 
reserves, using flocculating agents, and fillers in the slurry, or by limiting the openpanel width.

- Very tight verticality tolerances are necessary to assure continuity especially in deeper cut-offs. Such tolerances have been not only difficult to satisfy, but also difficult to measure accurately (to $\leq 0.5 \%$ of wall depth) and verify.

- The deepest panel walls have been installed at Wells Dam, WA (223 feet, clamshell) and at Mud Mountain Dam, WA (402 feet, hydromill). The hydromill has proved to be the method of choice for large cut-offs in fill, alluvial soils and in rock masses of unconfined compressive strengths less than 10,000 psi (massive) to 20,000 psi (fissile, and therefore, rippable).

- Secant pile cut-offs are expensive and intricate to build. However, they are the only option in certain conditions (e.g., heavily karstified, but otherwise hard limestone rock masses) which would otherwise defeat the hydromill. The deepest such wall (albeit a composite pile/panel wall) was the first - at Wolf Creek, KY in 1975 which reached a maximum of 280 feet. The most recent pure secant pile wall in carbonate terrain was at Beaver Dam, AR, 1992-1994.

- A wide range of backfill materials has been used, ranging from low strength plastic concrete, to conventional high strength concrete.

- The preparation and maintenance of a stable and durable working platform has proved always to be a beneficial investment, and its value should not be underestimated.

- The highest standards of real time $\mathrm{QA} / \mathrm{QC}$ and verification are essential to specify and implement. This applies to every phase of the excavation process, and to each of the materials employed.

- Enhancements have progressively been made in cut-off excavation technology, especially to raise productivity (particularly in difficult conditions), to increase mechanical reliability, and to improve the practicality and accuracy of deviation control and measurement.

\section{Potential Construction Issues with Cut-Offs}

Satisfactory construction of positive cut-off walls requires experience, skill, and dedication to quality in every aspect of the construction process including site preparation, excavation, trench or hole cleaning, concrete mixing, and concrete backfilling. Providing a positive cut-off requires that the elements of the wall be continuous and interconnected. The following issues are possible concerns that must be taken into account in wall construction to prevent defects.

- Element deviation - Misalignment of the equipment or inability to control the excavation equipment can result in deviation of elements and result in a gap in the completed wall.

- Uncontrolled Slurry Loss - Cut-off walls through existing water retaining structures are almost always built to address seepage issues. Although bentonite slurries are proven in creating a filter cake in soils, the ability of bentonite slurries to form a filter cake in rock fractures is limited. As a general rule of thumb, if water is lost during 
exploration, one should assume that slurry losses in rock will occur. If the rock is sufficiently pervious, uncontrollable complete slurry loss can occur. Slurry losses in embankments have also occurred on past projects due to hydrofracturing of weak zones. This is a particularly sensitive issue when excavating through epikarstic horizons, and major karstic features lower in the formation.

- Trench Stability - The factors of safety of slurry supported excavations in soil are not high. Movement of wedges into the trench or "squeeze in" of soft zones can occur.

- Concrete Segregation - Mix design and construction practices during backfill are critical to prevent segregation or honeycombing within the completed wall.

- Soil or Slurry Inclusions - The occurrence of soil or slurry filled defects or inclusions in completed walls are a known issue. If small or discontinuous, these defects are not critical, but they are very significant if they fully penetrate the width of the wall.

- Panel Joint Cleanliness - Imperfections or pervious zones along the joints between elements is a recognized source of leakage through completed walls. Cleaning of adjacent completed elements by circulating fresh slurry is necessary to minimize the contamination of joints.

\section{Performance}

Surprisingly little has in fact been published to date describing the actual efficiency of cut-off walls after their installation: most of the publications describe design and construction and have usually been written soon after construction by the contractors themselves. The soon to be published research into this matter by the Virginia Tech team of Rice and Duncan is, therefore, eagerly awaited. Although there is some published evidence (e.g., Davidson, 1990) that the walls have not always functioned as well as anticipated, it can be reasonably assumed that the majority of the remediations have been successful, provided a) the wall has been extended laterally and vertically into competent, impermeable and non-erodible bedrock; $b$ ) that there is full lateral continuity between panels with no clay contamination; and c) that the panels themselves contain no concrete segregations or slurry/soil inclusions. It may also be stated that the capabilities of the technology of the day have not always been able to satisfy the depth criterion. EM 11102-1901 published in 1986 by the USACE states that the experienced efficiency of cut-off walls calculated based on head reduction across the wall was $90 \%$ or better for properly constructed walls. The term "properly" is not defined and no update to this information has been published by the Government.

There is also the case of the diaphragm wall at Wolf Creek Dam, KY, the length and depth of which were restricted by the technology and funds available at the time. As a result, a new wall, deeper and larger, is about to be built to finally cut off the flow occurring through the deep, heavily karstified limestones. 


\section{GROUT CURTIANS}

\section{$\underline{\text { Design }}$}

- Designing grout curtains based on rules of thumb without consideration of the site geology is no longer an acceptable practice or standard of care. Contemporary approaches are based on the concept of a Quantitatively Engineered Grout Curtain (QEGC), which provides criteria for the maximum acceptable residual permeability and minimum acceptable dimensions of the cut-off (Wilson and Dreese, 1998, 2003).

- Prerequisite geological investigations and other work required to perform this quantitative design include:

- Thorough geologic investigations identifying structure, stratigraphy, weathering, and hydraulic conductivity of the foundation rock.

- Establishment of project performance requirements in terms of seepage quantities and seepage pressures. Design requirements should consider dam safety, cost, and political acceptability or public perception as they relate to residual seepage.

- Seepage analyses to determine the need for grouting, the horizontal and vertical limits of the cut-off, the width of the curtain, and the location of the curtain.

- Where relevant, the value of the lost water should be compared to the cost of more intensive grouting in a cost benefit analysis.

- Specifications written to require best practice for field execution of every element of the work.

- Quantitative design of grouting requires that the curtain be treated in seepage analyses as an engineered element. The specific geometry of the curtain in terms of depth and width must be included in the model and the achievable hydraulic conductivity of the curtain must also be assumed. Guidance on assigning grout curtain design parameters and performing seepage analyses for grout curtains is covered in detail by Wilson and Dreese (2003). More substantial and complete guidance on flow modeling of grouted cut-offs is included in the update to USACE EM 1110-2-3506 issued in 2008.

\section{$\underline{\text { Construction }}$}

Many aspects of the construction of QEGC's have also changed greatly in the last 10 years or so, driven by the goals of achieving improved operational speed and efficiency, satisfying lower residual permeability targets, enhancing $\mathrm{QA} / \mathrm{QC}$, verification and realtime control, and assuring long-term durability and effectiveness. Particularly important advances are as follows:

- The traditional concepts of stage grouting (i.e., up — or down - depending on the stability and permeability of the rock mass) and closure (i.e., Primary-SecondaryTertiary Phases) still apply. However, construction in two critical rows, with the holes in each inclined in opposite directions, has become standard practice.

- Balanced, multicomponent cement-based grouts are used, to provide high performance mixes which will have superior stability, rheological and durability 
properties. The use of "neat" cement grouts with high water:cement ratios and perhaps nominal amounts of superplasticizer or bentonite is simply not acceptable (Chuaqui and Bruce, 2003).

- The current state of the art in grouting monitoring and evaluation is a fully integrated system where all field instruments are monitored in real time through a computer interface, all necessary calculations are performed automatically, grouting quantity information is tabulated and summarized electronically, program analyses are conducted automatically by the system using numerous variables, and multiple, custom as-built grouting profiles are automatically generated and maintained realtime. This level of technology provides the most reliable and high quality project records with minimal operator effort. In fact, the advent of such technology has been found to substantially decrease grouting program costs while providing unprecedented levels of assurance that the design goal is being met (Dreese, et al., 2003).

- Modern drilling recording instruments and borehole imaging technology allow for better understanding of subsurface conditions than was previously possible. Measurement While Drilling ("MWD") instrumentation provides additional information during the drilling of every hole on a grouting project (Bruce and Davis, 2005). Specific energy and other recorded data can be evaluated and compared to the grouting data to procure as much information as possible from every hole drilled. Each hole on a grouting project is thereby treated as an exploration hole and the data gathered are utilized to increase the understanding of subsurface conditions. After a hole has been drilled, borehole imaging can be performed to obtain a "virtual core." This equipment is especially useful on destructively drilled production holes where recovered core is not available for viewing and logging, and provides invaluable data such as measurements of fracture apertures and bedrock discontinuity geometry. These are then utilized in designing or modifying the grout methods and materials. Borehole images are mapped by qualified personnel and the data may be further analyzed using stereonet analyses.

\section{VERIFICATION AND PERFORMANCE}

- Successfully achieving project closure is a three-step process: achieving closure on individual stages and holes; achieving closure on individual lines; and achieving closure on the entire curtain. Proper closure on individual stages and holes is primarily a function of the following items: drilling a properly flushed hole, effective washing of the hole, understanding the geology of the stages being grouted; applying that knowledge along with the results of water pressure testing to determine technically effective and cost effective stage selection; selecting appropriate starting mixes; real-time monitoring of the grouting and assessing its dynamic behavior in terms of characteristic signatures; making good and informed decisions regarding when to change grout mixes during injection within a stage; and managing the hole to completion (i.e., refusal to further grout injection) within a reasonable amount of time. The key is to gradually reduce the Apparent Lugeon Value of the stage (i.e., the 
Lugeon value calculated using grout as the test fluid, and taking into account the apparent viscosity of the grout relative to water) to practically zero.

- Pumping large quantities of grout for an extended period of time without any indication of achieving refusal is generally a waste of time and grout. Unless a large cavity has been encountered, the grout being used in this case has a cohesion that is too low and is simply traveling a great distance through a single fracture. Mix changes need to be managed properly for economy and value, especially in karstified conditions.

- Each line of a grout curtain and the completed curtain where multiple lines are installed should be analyzed in detail. Each section of the grout curtain should be evaluated and closure plots of pre-grouting permeability for each series in the section plotted. As grouting progresses, the plots should show a continual decrease in pregrouting permeability for each successive series of holes. For example, the results for the exploration holes and primary holes from the first line within a section represent the "natural permeability" of the formation. Secondary holes on each line should show a progressively reduced permeability compared to the primary holes due to the permeability reduction associated with grouting of the Primaries. Similarly, the pregrouting permeability of tertiary holes should show a marked decline relative to the secondary holes.

- In addition to performing the analyses described above, it is also necessary to review profiles indicating the geology, water testing, and grouting results. Review of the profiles with the water Lugeon values displayed on each zone or stage allows for confirmation that the formation behavior is consistent with the grouting, and permits rapid evaluation of any trends or problem areas requiring additional attention. In addition, this review permits identification of specific holes or zones within a hole that behaved abnormally and which are adversely skewing the results of the closure analysis. For example, the average pre-grouting permeability of tertiary holes that appear on a closure analysis plot may be 10 Lugeons, but that average may be caused by one tertiary hole that had an extraordinarily high value.

- Review of the grout line profiles with the grout takes displayed is also necessary along with comparison of the average grout takes compared to the average Lugeon values reported by the closure analysis. Areas of abnormally high or low grout takes in comparison to the Lugeon values should be identified for further analysis. The grouting records for these abnormal zones should be reviewed carefully along with the pressure testing and grouting records from adjacent holes. 


\section{“COMPOSITE" CUT-OFFS}

\section{$\underline{\text { Basic Premise }}$}

In recent years, there have been a number of projects, both completed and in planning, which have featured the construction of a concrete cut-off wall installed through the dam and into karstified carbonate bedrock. The basic premise of such a "positive" cut-off is clear and logical: the presence of large clay-filled solution features in the bedrock will defeat the ability of a grout curtain - even when designed and built using best contemporary practices - to provide a cut-off of acceptable efficiency and durability. This is particularly important when permanent "walk-away" solutions are required which must be robust, reliable and durable. There is no question that rock fissure grouting techniques are incompatible with satisfying that goal in the presence of substantial clayey infill materials. However, the benefits of a concrete cut-off come at a substantial premium over those provided by a grout curtain. A typical industry average cost for a grouted cut-off is of the order of $\$ 25-\$ 50$ per square foot. The cost of a concrete cut-off is anywhere from 4 to 10 times this figure, depending on the technique (i.e., panel or secant), the ground conditions, the depth of the cut-off, and the nature of the site logistics. Furthermore, the construction of a concrete cut-off wall through the typical karstified limestone or dolomite rock mass will involve the excavation of the rock (which in the main part will be in fact very hard, impermeable, and competent with UCS values in excess of 20,000 psi) and backfilling that thin excavation with a material of strength 4,000 psi or less. In effect, great effort and expense is expended to provide a membrane (through the greater part of the project) which is of lower strength than the rock mass excavated to construct it.

Another practical factor that has often been overlooked historically is that construction of a concrete wall may simply not be feasible in ground conditions which permit the panel trench stabilizing medium (i.e., bentonite slurry) or the drill flush (air or water) to be lost into the formation: in extremis either of these phenomena could create a dam safety threat, let alone the loss of very expensive excavation or drilling equipment at depth. The solution, not surprisingly, in such situations has been to suspend the wall construction and to systematically and intensively pretreat the formation by grouting.

In doing so, however, it has not been always the case that the designer of the wall has appreciated that, in addition to this campaign of drilling, water pressure testing and grouting constituting a facilitating improvement to the rock mass, such work also generates a most detailed site investigation - at very close centers - of the whole extent of the originally foreseen concrete cut-off area. It would be reasonable, therefore, to propose that the data from these pretreatment programs could be used to review the true required extent of the subsequent concrete wall, and thereby reduce overall project costs with sound engineering justification.

The concept may then be taken a stage further. Instead of drilling and grouting being conducted only as a remedial/facilitating operation under emergency conditions, specify it, as an originally foreseen designed concept to: 
- allow the location and extent of the major karstic features, which actually require cutoff with a concrete wall, to be precisely identified;

- pretreat the ground, and especially the epikarst, to an intensity that bentonite slurry or drill flush will not be lost during the concrete wall construction. A typical criterion is 10 Lugeons;

- grout, to a verified engineered standard, the rock mass around and under the karstic features and which does not contain erodible material in its fissures. A typical criterion is in the range 1-3 Lugeons.

By embracing these precepts, it is therefore logical to propose the concept of a "composite cut-off": an expensive concrete wall where actually required for long-term performance certitude, plus a contiguous and enveloping grout curtain to provide acceptable levels of impermeability and durability in those portions of the rock mass with minimal erodible fissure infill material.

\section{Illustrative Examples}

With one eye on the immediate future requirements of seepage remediation involving cut-offs under dams, it may be stated that karst is either stratigraphically driven, or structurally related. Figure $1 \mathrm{a}$ ) shows a case where the major horizon of long-term seepage and erosion concern is limited to the 30 feet or so of epikarst; Figure $1 \mathrm{~b}$ ) is the case where the seepage and erosion concern is in a particular deep stratigraphic member; and Figure $1 \mathrm{c}$ ) shows the condition where the karstification has developed along discrete structural discontinuities. For the sake of argument, assume that the cut-off has to be 1,000 feet long, the cost of drilling and grouting is $\$ 30$ per square foot, the concrete wall costs $\$ 120$ per square foot and the maximum vertical extent of the cut-off is 110 feet (a massive shale aquiclude exists at 100 feet). The dam itself is "invisible" in this exercise.

For the configuration of Figure $1 \mathrm{a}$ ), the original design features a concrete cut-off wall extending 10 feet into the aquiclude. The cost would therefore be 1,000 feet $\mathrm{x} 110$ feet $\mathrm{x}$ $\$ 120=\$ 13.2$ million. (This would, however, assume that construction of the wall through the epikarst would be feasible without pretreatment.) Alternatively, if the entire alignment were to be pregrouted, it would be revealed that there was no need to construct the wall deeper than, say 35 feet. The total cost of this composite wall would therefore be:

Drill and Grout: 1,000 feet $\times 110$ feet $\times \$ 30 /$ sft. $=$ Plus Wall: 1,000 feet $\times 35$ feet $\times \$ 120 /$ sft. $=$
$\$ 3.3$ million

$\$ 4.2$ million

$\$ 7.5$ million 


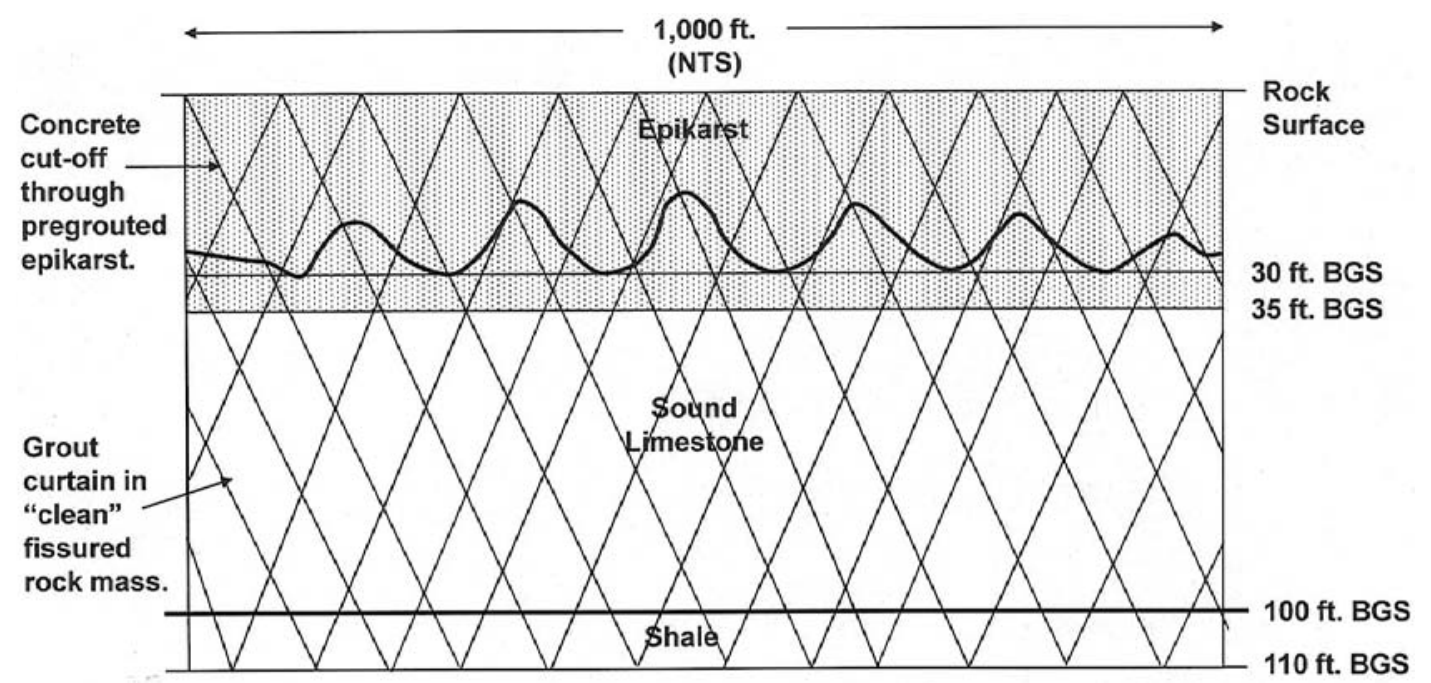

- Area of Grout Curtain (including pretreatment of epikarst) $=1,000 \mathrm{ft}$. $\times 110 \mathrm{ft}$. $=110,000 \mathrm{sft}$.

- Area of Subsequent Concrete Wall $=1,000 \mathrm{ft}$. $\times 35 \mathrm{ft}$. $=35,000 \mathrm{sft}$.

Figure $1 \mathrm{a}$ ). Epikarst is found during pregrouting to an average of 30 feet b.g.s. The concrete cut-off needs only to be installed to 35 feet b.g.s.

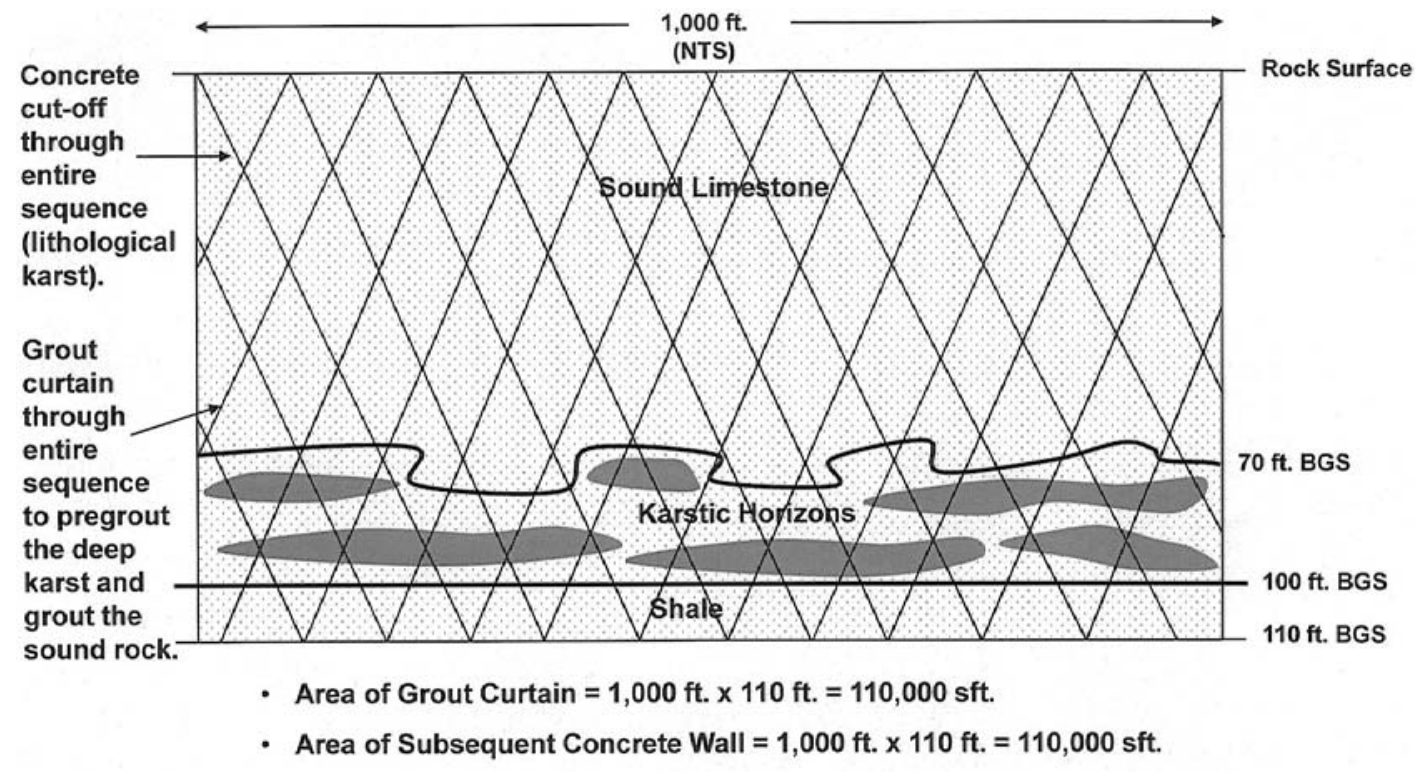

Figure $1 \mathrm{~b}$ ). Heavily karstified horizons are found at depth. Therefore the concrete cutoff is required for the full extent. The grouting has pretreated the karstic horizons to permit safe concrete cut-off construction. 


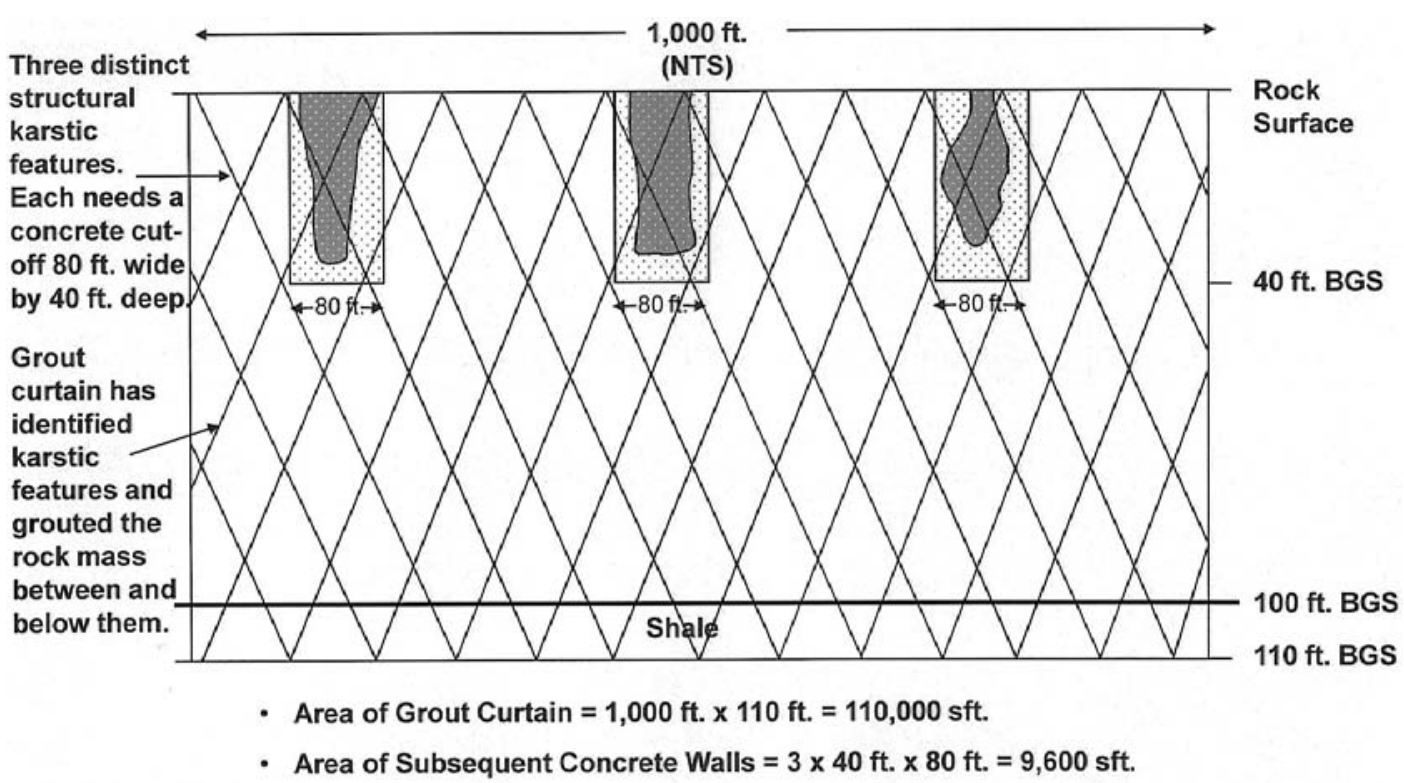

Figure $1 \mathrm{c}$ ). Discrete karstic features have been found, structurally driven. Thus, individual concrete cut-offs can be installed, after drilling and grouting have confirmed the extent of these features and have pretreated them to permit safe concrete cut-off construction.

- For configuration $1 \mathrm{~b}$ ), the cost of the predrilling and grouting would be the same, i.e., $\$ 3.3$ million. However, in this case, the concrete wall would have to be $\$ 13.2$ million. The overall cost of the cut-off would therefore be $\$ 16.5$ million. However, the pretreatment in advance of the concrete wall would assure that the wall could in fact be built in a cost-effective and timely fashion, i.e., without interruptions caused by massive slurry loss. The overall (high) project cost would simply be a reflection of a uniquely challenging geological situation, i.e., a continuous bed of erodible material at depth.

- For configuration $1 \mathrm{c}$ ), the pretreatment would again cost $\$ 3.3$ million. It would result in the identification of three discrete zones of structurally defined karst of combined area $3 \times 80$ feet $\times 40$ feet $=9,600 \mathrm{sq} f t$. Therefore, the cost of the concrete wall actually needed to cut these features off would be $9,600 \mathrm{sq} \mathrm{ft}$. $\mathrm{x} \$ 120 / \mathrm{sq} \mathrm{ft} .=$ $\$ 1,152,000$. Thus, the total cost of the composite wall is $\$ 3,300,000+\$ 1,152,000=$ $\$ 4.5$ million.

Thus, the investment in the predrilling and grouting program generates very large savings in cases a) and c), whereas for case b) it assures that the wall, which must be built, can be built without massive delays, difficulties, or - at worst - creating dam safety issues. 


\section{Recommendations for Grouting for a "Composite Wall"}

Site Investigation and Assessment and Design

- Research and utilize all the historical data (including original construction photographs) which may have bearing on the development of a tentative geostructural model. An excellent example is provided by Spencer (2006).

- Conduct a new, thoughtful and focused site investigation to test the tentative geostructural model and provide prospective bidders with the kinds of information they truly need to estimate productivity and to quantify other construction risks.

- Develop an initial estimate of the extent of the composite cut-off and its respective components, i.e., concrete wall and grout curtain.

- Assess the adequacy of the existing dam and foundation instrumentation, and design and install additional monitoring arrays as appropriate. Revise the reading frequency protocols as appropriate.

\section{Preparation of Contract Documents and Contractor Procurement Methods}

- Create a Performance (as opposed to Prescriptive) Specification, while at the same time clearly defining what methods and techniques are not acceptable. Performance goals must be explicitly defined, together with their means of verification.

- Procure the specialty contractor on the "Best Value" basis, not "Low Bid".

- Mandate "Partnering" as a minimum; favor "Alliancing" as the goal (Carter and Bruce, 2005).

- Perhaps separate general construction activities (e.g., office modifications, service relocation) into a different contract, but always leave the design and construction of the working platform to the specialist contractor.

\section{Technical Aspects}

- If flush water has been lost during investigatory drilling, slurry will certainly be lost during wall excavation, without pretreatment in those same areas.

- The minimum treatment intensity will feature two rows of inclined holes, one either side of the subsequent wall location. The rows may be 5 to 10 feet apart, and the holes in each row will typically close at 5 - to 10 -foot centers. The inclination (typically $15^{\circ}$ off vertical) will be different in each row.

- The curtain should be installed to at least 50 feet below and beyond the originally foreseen extent of the cut-off to assure adequate coverage and to search for unanticipated problems. The treatment must be regarded as an investigatory tool equally as much as a ground pretreatment operation and as a sealing of clean rock fissures.

- "Measurement While Drilling" principles are to be used; the philosophy being that every hole drilled in the formation (not just cored investigations) is a source of valuable geotechnical information. 
- Special attention must be paid to the epikarstic horizon, which will typically require special grouting methods such as MPSP (Multiple Packer Sleeve Pipe) (Bruce and Gallavresi, 1988) descending stages, and special grout mixes.

- A test section at least 100 feet long should be conducted and verified to allow finalization of the Method Statement for the balance of the grouting work. A residual permeability of 10 Lugeons or less should be sought in the area which is later to accept the cut-off, and lower in elevations below the future cut-off toe. Conversely, a falling head test in vertical verification holes, using bentonite slurry, is an appropriate test. Verification holes should be cored, and observed in situ with a televiewer to demonstrate the thoroughness of the grouting.

- In terms of the details of execution, the principles previously detailed to create Quantitatively Engineered Grout Curtains should be adopted. Thus, one can anticipate stage water tests; balanced, modified, stable grouts; and computer collection, analysis and display of injection data. When drilling the verification holes (at 25- to 100-foot centers between the two grout rows), particular care must be taken to assure that no drill rods are abandoned within the alignment of the wall since this steel will adversely impact subsequent wall excavation techniques.

- Grouting pressures at refusal should be at least twice the foreseen maximum slurry pressure exerted during panel construction.

\section{Construction}

- The work must be conducted in accordance with the Contractor's detailed Method Statement which, in turn, must be in compliance with the minimum requirements of the Specification unless otherwise modified during the bidding and negotiation process. At the same time, modifications to the foreseen means and methods can be anticipated on every project, in response to unanticipated phenomena. Prompt attention to, and resolution of, these challenges are essential.

- As noted above, special attention is merited to the details of the design and construction of the working platform. The Contractor's site support facilities (e.g., workshop, slurry storage and cleaning, concrete operations) can be completed and the utilities extended along the alignment (water, air, light, slurry) during the building of the work platform.

- The Test Section should be established in a structurally non-critical area, which does not contain the deepest extent of the foreseen concrete wall. The Test Section can, however, be integrated into the final works if it is proved to have acceptable quality.

- The concrete wall excavation equipment must have adequate redundancy, and must be supported by appropriate repair/maintenance facilities. A variety of equipment is usually necessary (clamshell, hydromill, chisels, backhoe) to best respond to variable site conditions and construction sequences. Standard mechanical features, such as the autofeed facility on hydromills, must not be disabled in an attempt to enhance productivity.

- The site laboratory must be capable of conducting accurately and quickly the whole range of tests required. In addition, the Contractor's Technical/Quality Manager, who is a vital component in any such project, must be fully conversant with all the principles and details involved in the monitoring of the construction, and of the dam 
itself. In particular, expertise with panel or pile verticality and continuity measurement is essential.

- Emergency Response Plans must be established to satisfy any event which may compromise dam safety.

\section{$\underline{\text { Assessment of Cut-Off Effectiveness }}$}

The protocols established for observations and instrument readings during remediation must be extended after remediation although usually at a somewhat reduced frequency. The data must be studied and rationalized in real time so that the remediation can be verified as meeting the design intent. Alternatively, it may become apparent that further work is necessary, a requirement that becomes clear only when the impact of the remediation of the dam/foundation system is fully understood. Finally, Owners and Designers should publish the results of these longer-term observations so that their peers elsewhere can be well briefed prior to engaging in their own programs of similar scope and complexity.

\section{FINAL REMARKS}

We arrive at an extraordinary and unprecedented time in the ongoing story of major dam rehabilitation in North America. Strengthened by decades of outstanding but hard won success and continuous technological developments, contractors who specialize in constructing concrete cut-offs through and under operational dams have now unprecedented expertise to offer to an industry craving their skills and resources. Grouting specialists - both contractors and consultants - have emerged to bring to the North American market a unique perspective and feeling for their work that is unparalleled historically and geographically. It is time to squash the false debate of "grouting vs. concrete walls." The obvious way forward is to take the best from each camp: drill, water test and grout (relatively cheaply) to prepare the ground for a concrete wall whose (relatively expensive) extent is now properly defined. Then, build, in improved ground conditions, the definitive concrete wall only in those areas where the grouting cannot be expected to be effective in the long term.

Our dams must be repaired, in a way that can be regarded as "permanent." However, there still remains the goal that we should ensure that our designs and implementations are cost-effective. Furthermore, there is simply insufficient industrial capacity in the U.S. to build the foreseen volume of cut-offs solely by concrete wall construction techniques in the time frame available. The concept of the "composite cut-off" is therefore logical, timely and the obvious choice.

\section{REFERENCES}

Bruce, D.A., A. Ressi di Cervia and J. Amos-Venti. (2006). "Seepage Remediation by Positive Cut-Off Walls: A Compendium and Analysis of North American Case Histories," Canadian Dam Association Conference, September 30 - October 5, Québec City, Québec. 
Bruce, D.A., (2007). "Dam Remediation by Anchors and Cut-Offs: A Summary of Two National Research Programs," $38^{\text {th }}$ Annual Ohio River Valley Soil Seminar, Louisville, KY, November 14, 35 pp.

Bruce, D.A. and J.P. Davis. (2005). "Quality and Quantification in Small Hole Drilling," Geo3 GEO Construction Quality Assurance/Quality Control Conference Proceedings, Editors D.A. Bruce and A.W. Cadden, Dallas/Ft. Worth, TX, November 6-9, pp. 271-282.

Bruce, D.A. and F. Gallavresi. (1988). "The MPSP System: A New Method of Grouting Difficult Rock Formations.” ASCE Geotechnical Special Publication No. 14, “Geotechnical Aspects of Karst ${ }^{\mathrm{TM}}$ Terrains." pp. 97-114. Presented at ASCE National Convention, Nashville, TN. May 10-11.

Carter, J. and D.A. Bruce. (2005). "Enhancing the Quality of the Specialty Contractor Procurement Process: Creating an Alliance," Geo ${ }^{3}$ GEO Construction Quality Assurance/Quality Control Conference Proceedings, Editors D.A. Bruce and A.W. Cadden, Dallas/Ft. Worth, TX, November 6-9, p 76-87.

Chuaqui, M. and D.A. Bruce. (2003). "Mix Design and Quality Control Procedures for High Mobility Cement Based Grouts." Grouting and Ground Treatment, Proceedings of the Third International Conference, Geotechnical Special Publication No. 120. Edited by L.F. Johnsen, D.A. Bruce, and M.J. Byle, American Society of Civil Engineers, New Orleans, LA, February 10-12, pp. 1153-1168.

Davidson, L. (1990). "Performance of the Concrete Diaphragm Wall at Navajo Dam," $10^{\text {th }}$ Annual USCOLD Conference, New Orleans, LA, March 6-7, 21 p.

Dreese, T., D.B. Wilson, D.M. Heenan, and J. Cockburn. (2003) "State of the Art in Computer Monitoring and Analysis of Grouting," Grouting and Ground Treatment, Proceedings of the Conference sponsored by the Geotechnical Engineering Division of the American Society of Civil Engineers, New Orleans, LA, February 10-12, pp. 14401453.

Halpin (2007). "Trends and Lessons in Assessing Risks Posed by Flood Damage Reduction Infrastructure," ORVSS XXXVIII, Ohio River Valley Soils Seminar, Louisville, KY, November 14.

Lombardi, G. (2003). "Grouting of Rock Masses." Grouting and Ground Treatment, Proceedings of the Third International Conference, Geotechnical Special Publication No. 120. American Society of Civil Engineers, New Orleans, LA, February 10-12, pp. 164197.

Walz, A.H., D.B. Wilson, D.A. Bruce, and J.A. Hamby. (2003). "Grouted Seepage Cutoffs in Karstic Limestone." Grouting and Ground Treatment, Proceedings of the Third 
International Conference, Geotechnical Special Publication No. 120. American Society of Civil Engineers, New Orleans, LA, February 10-12, pp. 967-978.

Weaver, K. and D.A. Bruce (2007). "Dam Foundation Grouting, Revised and Expanded Edition," American Society of Civil Engineers, ASCE Press, New York, 504 pp.

Weaver, K.D. and D.A. Bruce (2007). "Dam Foundation Grouting, Revised and Expanded Edition," American Society of Civil Engineers, ASCE Press, New York, 504 p.

Wilson, D. and T. Dreese (1998) "Grouting Technologies for Dam Foundations," Proceedings of the 1998 Annual Conference, ASDSO, Las Vegas, Nevada.

Wilson, D. and T. Dreese (2003) "Quantitatively Engineered Grout Curtains," Grouting and Ground Treatment, Proceedings of the Conference sponsored by the Geotechnical Engineering Division of the American Society of Civil Engineers, New Orleans, LA, February 10-12, pp. 881-892.

USACE (1986) EM 1110-2-1901.

USACE (2008) EM 1110-2-3506. 